
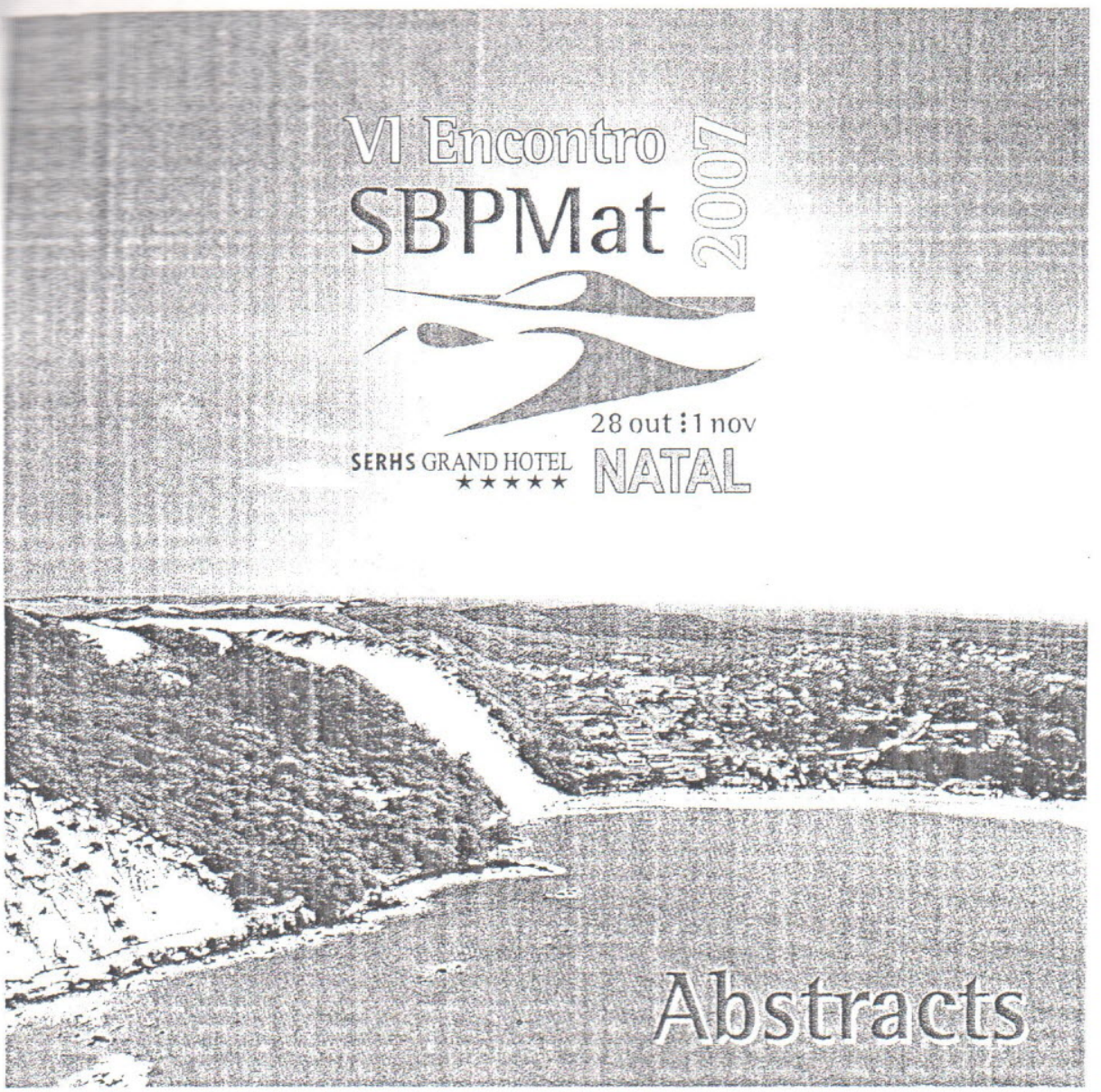


\title{
SPID 10824
}

$\underbrace{\text { SBPMat }}_{-}$

6th Brazilian MRS Meeting

\section{Role of the Oriented Attachment Mechanism in the Phase Transformation of Oxide Nanocrystals}

\author{
Caue Ribeiro ${ }^{(1)}$, Cristiane Vila ${ }^{(2)}$, José Milton Elias de Matos $^{(3)}$, Elson Longo ${ }^{(4)}$ and Edson R. Leite ${ }^{(2)}$
}

(1) EMBRAPA Instrumentação Agropecuária. Rua XV de Novembro, 1452 - 13560-970, CP 741 , São Carlos, SP, Brazil (fax +55 163372 5958). caue@cnpdia.embrapa.br

(2) LIEC / Universidade Federal de São Carlos, Departamento de Quimica. Rod. Washington Luiz, km 235 - 13565-905, São Carlos, SP, Brazil (fax +55 163351 8214). derl@power.ufscar.br

(3) Universidade Federal do Piauí, Departamento de Química. Campus Min. Petrônio Portela 64049-550, Teresina, PI, Brazil (fax +55 893215 5840). jmematos@liec.ufscar.br

(4) LIEC / Universidade Estadual Paulista, Instituto de Quimica. Rua Francisco Degni, s/n - 14800900, Araraquara, SP, Brazil (fax +55 1632016600$)$. elson@liec.ufscar.br

Abstract - The synthesis of titanium and zirconium oxide in the nanometric range is reported by a novel route based on the decomposition of peroxide complexes of the two metals under hydrothermal soft conditions, obtaining metastable and stable phases in both cases through transformation. High-resolution transmission electron microscopy analysis reveals the existence of typical defects relating to growth by the oriented attachment mechanism in the stable crystals, suggesting that the mechanism is associated to the phase transformation of these structures.

It is generally understood that, in the synthesis of nanomaterials, many metastable structures appear as preferential in nanometric range, without the addition of dopants or constriction by a matrix. The occurrence of stable phases is observed only in some specific cases, often associated with anisotropic shapes. Recent investigations into oriented attachment crystal growth ${ }^{2}$ have demonstrated that this mechanism favors the formation of anisotropic nanocrystals by the coalescence of two or more nanocrystals. Thus, one can assume that the fast growth and the anisotropic shapes obtained can give rise to other phenomena relating to shape and size, such as spontaneous phase transformation. In this work, it is shown that the phase transformation of two well-known oxide systems $-\mathrm{TiO}_{2}$ and $\mathrm{ZrO}_{2}-$ is followed by crystal growth by the oriented attachment mechanism. To this end, a hydrothermal route under soft conditions, based on the decomposition of peroxide complexes of the two metals, was used. The morphology and particle size distribution of both systems were characterized using transmission electron microscopy (by image statistics) and X-ray diffraction patterns, using Scherrer equation to estimate sizes in several crystallographic directions. A general correlation of the growth by oriented attachment, leading to anisotropic nanoparticles, and the stabilization of non-expected phases in the measured sizes $\left(\mathrm{TiO}_{2}\right.$ rutile, as shown in Fig. 1 and $\mathrm{ZrO}_{2}$ baddeleyte) was observed, suggesting that the mechanism is associated to the phase transformation of these structures. It should be noted that the role of oriented attachment is to modify the Area/Volume relation in the formed particles, favoring or not (as in the case of $\mathrm{ZrO}_{2}$ tetragonal, in Fig. 2) the phase transformation according the exposed crystallographic planes after the event - that can be interpreted as the minimization of the total surface energy related to the phase stabilization in non-spherical shapes.

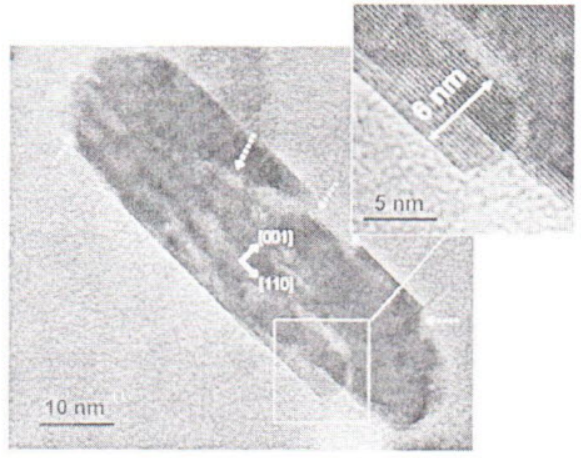

Figure 1: $\mathrm{TiO}_{2}$ - rutile nanoparticle with lateral coalescence

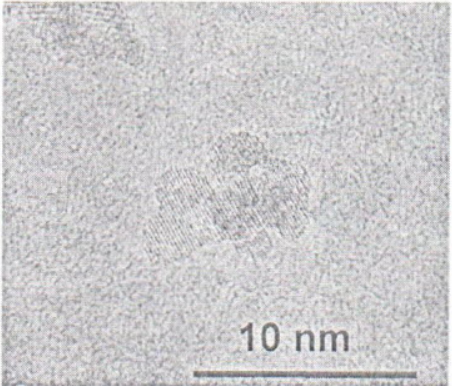

Figure 2: $\mathrm{ZrO}_{2}$ - tetragonal nanoparticles coalesced

\section{References}

[1] Navrotsky, A. Proc. Natl. Acad. Sci. U. S. A., 101, 2004, 12096-12101

[2] Lee, E.J.H.; Ribeiro, C.; Longo, E. \& Leite, E.R. J. Phys. Chem. B. 109, 2005. 20842-20846 